\title{
Kajian Biblika Tentang Penyesatan Berdasarkan Matius 18:6- 11 Dan Implementasinya Dalam Kehidupan Orang Percaya
}

\author{
Pradini Betelin Obed, Armin Sukri
}

\begin{abstract}
Abstrak
Tujuan penelitian ini adalah untuk mendapatkan makna dari kata penyesatan berdasarkan Matius 18:6-11. Adapun metode yang digunakan penulis dalam penelitian ini adalah metode kualitatif yaitu metode penelitian kepustakaan (library research), terhadap sumber data antara lain: Alkitab, tafsiran-tafsiran dan buku-buku yang berhubungan tentang "Penyesatan" sesuai konteks Matius 18:6-11 dan disertai bantuan media elektronik. Sedangkan prinsip hermeneutik yang dikerjakan penulis adalah mengemukakan latar belakang konteks nas, menguraikan stuktur nas dan terakhir menemukan makna konteks berdasarkan nas yang dipilih

Berdasarkan tujuan dan metode yang digunakan penulis di atas maka penulis mendapatkan hasil penelitian sebagai berikut: Pertama, penyesatan yang dimaksud mengacu kepada adanya kesalahan konsep tentang Kerajaan Allah yang dipikirkan oleh murid-murid pada waktu itu. Mereka memandang Kerajaan Sorga dalam konsep politis untuk keuntungan mereka sendiri. Kedua, orang yang disesatkan bukan semata-mata seorang anak tetapi orang yang lemah imannya yang membutuhkan pengajaran Firman Tuhan. Ketiga, harus menjadi seperti anak kecil artinya adalah tidak memiliki kesombongan dan bergantung penuh kepada Tuhan.
\end{abstract}

Kata kunci: Penyesatan, Anak Kecil, Kerajaan Surga, Konsep Politis.

\section{Pendahuluan}

\section{Latar Belakang Masalah}

Gereja Tuhan yang sedang bertumbuh di tengah dunia ini dihadapkan dengan berbagai macam tantangan dan pergumulan yang ada. Tantangan maupun pergumulan tersebut datang dari berbagai sumber, baik sumber dari dalam maupun dari luar gereja itu sendiri. Dari luar gereja telah terjadi penganiayaan, penindasan dan penolakan terhadap Injil di beberapa tempat. Sedangkan yang di dalam gereja adalah pertikaian, keduniawian dan kehidupan para tokoh gereja yang tidak bertanggung jawab serta merambatnya banyak pengajaran sesat atau penyesatan. Ivan Weismann menggunakan istilah "pelecehan rohani" untuk menggambarkan masalah-masalah yang muncul dalam gereja, sebagai berikut:

Pelaku pelecehan rohani muncul dalam segala bentuk, ukuran, kepercayaan, dan warna. Mereka memilih korban berdasarkan seberapa banyak kekuasaan dan kontrol 
yang bisa mereka terapkan atas seseorang. Siapapun berpotensi menjadi korban. Pelecehan rohani terjadi ketika mereka (para pemimpin gereja/rohani dalam jemaat) menyalahgunakan otoritas yang dimiliki agar dapat menguasai atau mengendalikan orang lain dalam kehidupan beragama atau dalam bidang rohani. Penderitaan, timbulnya perasaan negatif, bahkan depresi adalah reaksi normal terhadap pelecehan rohani. ${ }^{1}$

Keadaan ini tentu menjadi suatu keadaan yang mengkhawatirkan. Selain itu, Erastus Sabdono mengungkapkan, "Dari berbagai tantangan dan tekanan yang dapat menghambat atau bahkan menghancurkan laju gereja Tuhan, pengajaran sesat atau penyesatan adalah salah satu bahaya yang harus ditanggapi serius." "Persoalan mengenai pengajaran sesat atau penyesatan ini telah menjadi pergumulan Tuhan sejak masa gereja mula-mula hingga sampai zaman ini. Sejak zaman rasul-rasul ada banyak penyesat atau nabi palsu telah bermunculan di tengah kehidupan jemaat Tuhan dan merusak pengajaran di dalam gereja. Bahkan pada abad-abad berikutnya, gereja masih menghadapi keadaan yang sama seperti Marsionisme, Liberalisme, Radikalisme dan seterusnya.

Matius 18:6-11 adalah sebuah perikop yang disampaikan oleh Yesus dalam pengajaran-Nya mengenai penyesatan. Yesus menyampaikan dengan jelas bahwa penyesatan itu memang ada dengan tujuan sebagai sarana yang dipakai oleh Allah untuk mendisiplinkan dan juga membentuk watak orang percaya. ${ }^{3}$ Bukan berarti bahwa Kristus menyuruh melakukan penyesatan tetapi ini merupakan perkiraan yang dibuat-Nya berdasarkan alasan tertentu seperti adanya tipu daya dan kelicikan iblis, kelemahan dan kebejatan hati manusia serta kebebalan mereka atau bahkan secara moral. ${ }^{4}$ Tetapi Yesus juga mengatakan dengan keras bahwa celakalah orang-orang yang mengadakan penyesatan, dan akan ada hukuman yang akan diberikan kepada penyesat-penyesat itu.

Jika penyesatan ada untuk menyatakan kemuliaan Allah, tetapi sulit untuk dimengerti maksud narator mengenai hal ini terutamabahwa penyesatan dapat dipakai untuk maksud yang mulia ini. Jelas, bahwa sebenarnya penyesatan menghadirkan banyak masalah bukan sebaliknya. Peringatan Yesus bukan sekedar larangan bagi orang untuk menyesatkan orang lain tetapi juga supaya waspada terhadap para penyesat. Identitas para penyesat serta penyesatan seperti apa yang dilakukan membuahkan perdebatan diantara para penafsir. Matthew Henry mengemukakan bahwa penyesatan itu dilakukan oleh diri kita sendiri karena adanya godaan dosa yang pada umumnya berasal dari keinginan daging. ${ }^{5}$ Sedangkan penafsir lainnya yaitu Gregorius Suwito berkata bahwa "Karakteristik dari penyesat adalah nabi palsu yang memalsukan pesan Tuhan". ${ }^{6}$ Ini menjadi hal yang aneh karena ada pendapat yang berbeda-beda mengenai sumber dan pelaku penyesatan. Mengenai jenis penyesatan,Morris mengungkapkan, "Menyesatkan mengandung arti menjebak dan Yesus tidak mendetailkan

\footnotetext{
${ }^{1}$ Ivan. Th. J. Weismann, Pelecehan Rohani Dalam Gereja (Bandung: Kalam Hidup, 2017), iii-iv.

${ }^{2}$ Erastus Sabdono, Penyesatan yang Terselubung (Jakarta: Rehobot Literature,2017), 13.

${ }^{3}$ Charles F. Pfeiffer dan Everett F. Harrison, Tafsiran Alkitab Wyclife Volume 3 Perjanjian Baru(Malang: Gandum Mas, 2001), 85.

${ }^{4}$ Matthew Henry, Tafsiran Matthew Henry: Injil Matius 15-28 (Surabaya: Momentum, 2008), 881.

${ }^{5}$ Matthew Henry, Tafsiran Matthew Henry: Injil Matius 15-28 (Surabaya: Momentum, 2008), 881.

${ }^{6}$ Gregorius Suwito, "Identitas Nabi Palsu dalam Matius 7:15-29," Jurnal Teologi dan Pengembangan Pelayanan 6, No. 1 (Juli 2016):7.
} 
satu dosa spesifik."7 Henry langsung menambahkan bahwa maksud dari penyesatan yang tersebut yaitu godaan-godaan dan hasrat duniawi yang membawa kecemaran sehingga menyesatkan manusia dari kebaikan ke dalam kejahatan serta perbuatan-perbuatan yang menyengsarakan jiwa orang-orang yang benar. ${ }^{8}$

Kenyataan yang terjadi saat ini adalah kebanyakan gereja tidak menyadari bahwa mereka sedang disesatkan dalam hal iman mereka kepada Kristus. Seperti yang dilansir dalam Majalah Tempo edisi 3 Juli 2005, mengisahkan Pendeta Robert P. Walean yang mengajarkan "Islam Hanif" kepada jemaat Advent, dimana beliau mengatakan bahwa umat Islam adalah golongan umat yang diterima oleh Tuhan. ${ }^{9}$ Pernyataan ini akhirnya menyebabkan pro dan kontra di kalangan Jemaat bahkan pendeta Gereja Advent. Begitu pula Dji Ali Sugito, S.Th yang telah terang-terang menyatakan bahwa, "Alkitab bukanlah Firman Allah yang setiap kata-kata atau pemikirannya harus ditaati secara mutlak oleh manusia di sepanjang zaman." 10 Pernyataannya membuahkan suatu perdebatan karena terlontar dari seorang pendeta yang tiap hari mengajarkan tentang Firman Tuhan. Jika Gereja secara terang-terangan menghadapi pengajaran agama lain, mudah mengantisipasinya. Tetapi kalau penyesatan yang dihadapi adalah sesuatu yang sangat tersembunyi dan bahkan tidak diketahui suatu penyesatan, maka akan lebih sukar untuk mengenali maupun mengantisipasinya.

Penyesatan muncul dalam berbagai bentuk dan dari berbagai sumber yang seringkali tanpa disadari oleh gereja. Terdapat ajaran-ajaran teologia dan aliran-aliran gereja yang dinilai oleh aliran lainnya sebagai penyesat. Sebagai contoh, Gerakan Saksi-Saksi Yehova yang kemudian dikenal dengan GSSY adalah salah satu bentuk penyesatan yang saat ini sedang dihadapi oleh gereja. Gerakan ini juga memegang alkitab sebagai kitab suci namun mereka menginterpretasikan alkitab berdasarkan penalaran manusia. Dengan menggunakan pendekatan ini Charles Taze Russell sebagai pendiri GSSY mengembangkan teologi "Kebenaran yang Hadir"-nya yang dikarakterisasikan dengan penolakan kepada setiap doktrin Kristen utama dan mencapnya sebagai tidak dapat dipahami dengan nalar, dan tidak alkitabiah. ${ }^{11}$ Dalam hubungannya dengan ajaran teologia, saat ini berkembang misalnya ajaran atau teologia hyper grace disebabkan oleh kurangnya jemaat dalam memahami alkitab tersebut dan akhirnya membuahkan pengajaran alkitab yang ditambah sesuai dengan kebutuhan sehingga Firman Tuhan menjadi tidak murni lagi. ${ }^{12}$ Banyak pengajaran atau khotbah yang nampaknya didasarkan pada ayat Alkitab tetapi sebenarnya tidak alkitabiah.Hal ini biasanya dikarenakan adanya kesalahan dalam hal penafsiran dan juga konsep teologi dari pengkhotbah sendiri. Tentunya yang menjadi tolak ukur adalah berdasarkan Alkitab tetapi realitas saat ini adalah kurangnya pemahaman yang mendalam terhadap isi Firman Tuhan sehingga jemaat sulit untuk membedakan mana yang sesat dan

\footnotetext{
${ }^{7}$ Leon Morris, Injil Matius (Surabaya: Penerbit Momentum, 2016), 470.

${ }^{8}$ Matthew Henry, Tafsiran Matthew Henry: Injil Matius 15-28 (Surabaya: Momentum, 2008), 881.

9 ,“Gereja Nyaris Bertauhid,” Tempo, 3 Juli 2005, 58.

${ }^{10}$ Adji Ali Sugioarto, "Klaim Palsu dan Sikap Eksklusif Fundamentalis-Injili: Suatu Ancaman bagi Masa Depan Hubungan Antar Agama.” Penuntun 5/19 (2003): 263

11“Tentang Saksi-Saksi Yehova" diakses 24 Juli 2018, http://www.gkihalimun.org/kegiatanpembangunan-jemaat/artikel-bina-iman/tentangsaksi-saksiyehova

12“Hati-hati Dengan Penyesatan Dengan Kedok Hyper Grace” diakses 22 Februari 2018,http://www.gbi-bethel.org/hati-hati-dengan-penyesatan-dengan-kedok-hyper-grace/.
} 
yang benar. Tentunya jemaat tidak dapat langsung menyimpulkan bahwa salah satu penyesat yang terselubung dalam gereja adalah gembala mereka sendiri.

\section{Pokok Masalah}

Sesuai dengan penjelasan latar belakang, yang menjadi pokok masalah penulisan karya ilmiah ini adalah:

Pertama, apa yang dimaksud dengan penyesatan berdasarkan Matius 18:6-11?

Kedua, apa implementasi penyesatan dalam kehidupan orang percaya masa kini?

\section{Tujuan Penelitian}

Pertama, untuk menjelaskan apa yang dimaksud dengan penyesatan berdasarkan Matius18:6-11.

Kedua,membahas implementasi dari penyesatan dalam kehidupan orang percaya saat ini.

\section{Manfaat Penelitian}

Adapun manfaat dari penulisan tentang penyesatan ini adalah:

Pertama, supaya tulisan ini dapat menjadi bahan bacaan yang dapat menambah wawasan bagi para pembaca.

Kedua, agar dapat menjadi acuan serta dasar Alkitabiah dalam pengajaran tentang penyesatan

Ketiga, untuk memenuhi salah satu syarat dalam menyelesaikan Stratum Satu (S-1) Program Studi Teologi Kristen pada Sekolah Tinggi Theologia Jaffray Makassar.

\section{Metode penelitian}

Adapun metode yang digunakan dalam penelitian ini adalah metode kualitatif yaitu metode penelitian kepustakaan (library research), terhadap sumber data antara lain: Alkitab, tafsiran-tafsiran dan buku-buku yang berhubungan tentang "Penyesatan" sesuai konteks Matius 18:6-11 dan disertai bantuan media elektronik

\section{Batasan Penelitian}

Dalam penulisan ini, penulis memberikan batasan tentang penyesatan berdasarkan Matius 18:6-11. Adapun tafsiran serta teori-teori yang berkembang mengenai pokok bahasan penulis hanyalah sebagai referensi, acuan serta ide-ide untuk membantu memperlengkapi keabsahan penulisan karya ilmiah ini.

\section{Kesimpulan}

Berdasarkan seluruh uraian penulis melalui skripsi ini, maka penulis menarik kesimpulan tentang kajian biblika kata penyesatan dalam Matius 18:6-11 yaitu sebagai berikut:

Pertama,penyesat adalah orang-orang fasik yang menyepelehkan iman orang kecil dengan menanamkan suatu prinsip yang keliru dan tidak berdasarkan Firman Tuhan.

Kedua, makna penyesatan adalah adanya persepsi yang keliru tentang Kerajaan Allah yang dipandang sebagai upah mengikut Kristus padahal yang Yesus maksudkan bahwa penderitaan yang akan menjadi konsekuensi mengikut Dia. 
Ketiga, orang yang disesatkan adalah orang-orang kecil atau sederhana yang sering dianggap remeh.

Keempat, Yesus memberikan peringatan untuk tidak menganggap rendah dan tidak menyesatkan anak kecil.

Kelima, adanya hukuman yang serius yaitu pelemparan ke neraka bagi orang yang melakukan penyesatan.

Keenam, ada malaikat yang akan senantiasa melindungi orang yang takut akan Tuhan.

Ketujuh, Allah datang untuk menyelamatkan orang-orang yang terhilang, melindungi mereka dan memastikan kebahagiaan mereka.

\section{Kepustakaan}

Barclay, Wiliam. Pemahaman Alkitab Setiap Hari Injil Markus. Jakarta: BPK Gunung Mulia 2003.

Barclay, Wiliam. Pemahaman Alkitab Setiap Hari Injil Matius pasal 11-28. Jakarta: BPK Gunung Mulia, 2003.

Bergant, Dianne., dan Robert J. Karris. Tafsir Alkitab Perjanjian Baru. Yogyakarta: Penerbit Kanisius, 2002.

Blomberg, Craig. The New American Commentary Vol. 22: Matthew. Nashville: Broadman \& Holman Publishers, 2001.

Brake, Andrew. Keunggulan Kristus dan Kerajaan Allah: Refleksi-refleksi dari Matius 9-20. Makassar: Sekolah Tinggi Theologia Jaffray, 2018.

Brake, Andrew. Spiritual Formation. Bandung: Kalam Hidup, 2014.

Bruggen, Jacob Van. Markus Injil Menurut Petrus. Jakarta: BPK Gunung Mulia, 2006.

Elwell, Walter A. (ed.). Baker Encyclopedia of the Bible. Grand Rapids: Baker Book House, 1988.

Douglas, J. D. (ed.). Ensiklopedia Alkitab Masa Kini Jilid M-Z. Jakarta: OMF, 1995.

Gering, Howard M. Analisa Alkitab. Jakarta: Yayasan Pekabaran Injil 'Imanuel', 1992

Heer, J. J. Tafsiran Injil Matius. Jakarta: BPK Gunung Mulia, 2003.

Henry, Matthew. Tafsiran Matthew Henry: Injil Matius 15-28. Surabaya: Momentum, 2008.

Hymers Jr, R. L. The Church That Will Be Left Behind. Oklahoma: Heathstone Publishing, 2001.

Leks, Stefan. Tafsir Injil Matius. Yogyakarta: Penerbit Kanisius, 2003.

Morris, Leon. Injil Matius. Surabaya: Momentum, 2016.

Mounce, Robert H. Understanding The Bilble Commentary Series: Matthew. USA: Baker Books, 2011.

Nur, Aslam. "Kearifan Lokal Dan Upaya Penanggulangan Aliran Sesat Di Aceh.” Jurnal Adabiya 18 (35) (2017): 1-16.

Ord, David Robert., dan Robert B. Coote. Apakah Alkitab itu Benar? Jakarta: BPK Gunung Mulia, 2013.

Pasaribu, Marulak. Eksposisi Injil Sinoptik: Mengenal Yesus yang Diberitakan dalam Injil Matius, Markus, dan Lukas. Malang: Gandum Mas, 2005.

Pfeiffer, Charles F., dan Everett F. Harriso. Tafsiran Alkitab Wycliffe Vol. 3 Perjanjian Baru. Malang: Gandum Mas, 2001. 
Rumante, Simon. "Teologi Biblika Perjanjian Baru Tentang Hakim Yang Akan Datang: Kajian Tentang Eskatologi Dalam Perjanjian Baru Dan Implementasinya Dalam Pendidikan Agama Kristen Di Sekolah" Jurnal Jaffray[Online], Volume 9 Number 1 (3 April 2011)

Ryle, J. C. Expository Thoughts on Matthew. USA:The Banner of Truth Trust: 2011. Sabdono, Erastus. Penyesatan yang Terselubung. Jakarta: Rehobot Literature, 2017. Sajari, Dimyati. "Fatwa Mui Tentang Aliran Sesat Di Indonesia (1976-2010)." MIQOT: Jurnal Ilти-Ilти Keislaman 39 (1) (2015): 44-62. http://jurnalmiqotojs.uinsu.ac.id/index.php/jurnalmiqot/article/view/38.

Santoso, David Iman. Theologi Matius: Intisari dan Aplikasinya. Malang: Literatur SAAT, 2009.

Suwito, Gregorius. "Identitas Nabi Palsu dalam Matius 7:15-29." Jurnal Teologi dan Pengembangan Pelayanan. No. 1 (Juli 2016): 1-30.

Soedarmi, R. Makna Ungkapan-Ungkapan Asing dalam Alkitab. Jakarta: BPK Gunung Mulia, 2004.

Sosipater, Karel. Etika Perjanjian Baru. Jakarta: Suara Harapan Bangsa, 2010.

Suharyo, L. Pengantar Injil Sinoptik. Yogyakarta: Kanisius, 1995.

Tenney, Merril C. Survei Perjanjian Baru. Malang: Gandum Mas, 1961.

Wauran, Queency. "Kajian Biblika Kecemburuan Allah Terhadap Penyembahan Berhala Berdasarkan Keluaran 20:4-6." Jurnal Jaffray [Online], Volume 13 Number 2 (29 September 2015).

Weismann, Ivan. Th. J. Pelecehan Rohani Dalam Gereja. Bandung: Kalam Hidup, 2017.

Wiersbe, Warren W. Loyal di dalam Kristus: Mengikuti Raja Segala Raja. Bandung: Yayasan Kalam Hidup, 2012. 